Current Issues of Education and Science, 2021

Conference proceedings. ISBN: 978-617-7089-14-7

https://doi.org/10.26697/9786177089147.2021

HEALTH CARE SCIENCE

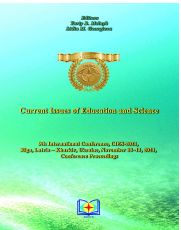

DOI: https://doi.org/10.26697/9786177089147.2021.10

\title{
Modern Endobronchial Methods in the Treatment of Chronic Lung Abscesses
}

\section{Anton A. SERENKO ${ }^{1}$ (D), Vasiliy G. HROMA ${ }^{1,2}{ }^{\mathbb{D}}$, Dmytro V. MINUKHIN ${ }^{2}$, Denys O. YEVTUSHENKO' ${ }^{2}$}

${ }^{I}$ State Institution "V. T. Zaitsev Institute of General and Urgent Surgery of the National Academy of Medical Sciences of Ukraine", Ukraine

${ }^{2}$ Kharkiv National Medical University, Ukraine

\section{Corresponding Author Details}

Denys O. YEVTUSHENKO,dr.yevtushenko@ukr.net

Received: 29.08.2021; Accepted: 21.09.2021; Published: 27.12.2021

\section{Brief Summary}

Background: The problem of treatment of chronic lung abscesses remains incomplete despite the achievements of modern medical science. There is a clear trend towards the spread of the number of patients with this pathology. One of the ways to improve the results of treatment of patients with chronic lung abscesses is to find new ways to treat this disease, in particular with the help of endobronchial methods of rehabilitation and correction of the activity of oxidative-antioxidant systems of the body.

The aim of the study: To investigate the effectiveness of endobronchial methods in the treatment of chronic lung abscesses using various drug compositions.

Methods: Examination and treatment of 98 patients with chronic lung abscesses was performed on the basis of the Department of Thoracic and Abdominal Surgery of State Institution " $V$. T. Zaitsev Institute of General and Urgent Surgery of the National Academy of Medical Sciences of Ukraine". Patients were divided into two groups: main and comparative. Patients of the main group together with anti-inflammatory drugs were 
systemically and locally prescribed liposomal drug. Standard methods were used in patients of the comparative group.

Results: The effectiveness of endobronchial methods of treatment of chronic abscesses has been proven by positive dynamics of ultrasound diagnostics at an earlier date than in the case of standard treatments. Based on the analysis of laboratory parameters, a significant positive effect of the applied method on reducing the level of endogenous intoxication was established.

Conclusions: The obtained data demonstrate significantly higher efficiency of the proposed method of endobronchial treatment of patients with chronic lung abscesses, including a combination of drainage and rehabilitation of the destruction cavity with anti-inflammatory therapy and its advantage over standard treatment regimens, accompanied by faster statistically significant regression endogenous intoxication.

\title{
Keywords:
}

chronic lung abscess, endobronchial treatments, endobronchial methods, patient, therapy.

\section{Сучасні ендобронхіальні методи в лікуванні хронічних абсцесів легень}

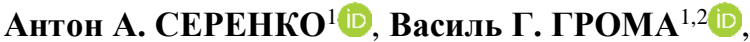 \\ Дмитро В. МІНУХІН ${ }^{2}$, Денис О. СВТУШЕНКО 2 \\ ${ }^{1}$ ДУ “Інститут загальної та невідкладної хірургії ім. В. Т. Зайцева \\ НАМН Украӥни”, Украӥна \\ ${ }^{2}$ Харківський національний медичний університет, Україна
}

Деталі Автора-Кореспондента:

Денис О. Свтушенко, dr.yevtushenko@ukr.net

\begin{abstract}
Анотація
Bcmyn: Незважаючи на досягнення сучасної медичної науки, проблема лікування хронічних абсиесів легень залишається не до кіния вирішеною. Спостерігається чітка тенденція до поширення кількості хворих з иією патологією. Одним із шляхів поліпшення результатів лікування хворих з хронічними абсиесами легень є пошук нових способів лікування цьвого захворювання, зокрема за допомогою ендобронхіальних методів санації та корекиії активності оксидантно-антиоксидантної систем організму.
\end{abstract}


Мета дослідження: Дослідити ефективність застосування ендобронхіальних методів у лікуванні хронічних абсиесів легень 3 використанням різних лікарських композицій.

Методи: На базі відділення торако-абдомінальної хірургії ДУ "Інститут загальної та невідкладної хірургї̈ ім. В. Т. Зайцева НАМН України” проведено обстеження та лікування 98 хворих з хронічними абсиесами легенів. Хворих розподілили на дві групи: основну та порівняльну. Хворим основної групи разом із протизапальними препаратами системно та місиево призначали ліпосомальний препарат. У хворих порівняльної групи застосовували стандартні методи.

Результати: Ефективність ендобронхіальних методів лікування хронічних абсиесів доведена позитивною ультразвуковою динамікою в більш ранні строки, ніж у разі застосування стандартних методів лікування. На підставі аналізу лабораторних показників встановлено суттєвий позитивний вплив застосованої методики на зниження рівня показників ендогенної інтоксикації.

Висновки: Отримані дані демонструють вірогідно більш високу ефективність запропонованого методу ендобронхіального лікування хворих на хронічні абсцеси легень, щзо включає комбінацію дренування та санації порожнини деструкції з протизапальною терапією та його перевагу перед стандартними схемами лікування, що супроводжувалося більш швидким статистично достовірним регресом патологічного процесу та суттєвим зниженням рівня ендогенної інтоксикації.

\section{Ключові слова:}

хронічний абсиес легені, ендобронхіальне лікування, ендобронхіальні методи, пацієнт, терапія.

\section{Вступ:}

Незважаючи на стрімкий розвиток медичної науки, проблема лікування хронічних абсцесів легень залишається не до кінця вирішеною. Спостерігається чітка тенденція до поширення кількості хворих на цю патологію (Boiko et al., 2007; Kotiv et al., 2009; Nicolini et al., 2014).

Довготривала наявність гнійного процесу в легенях збільшує можливість виникнення тяжких та небезпечних для життя ускладнень (кровотеч, септикопіємій та ін.), розвитку незворотних змін серцево- 
судинної системи, системи дихання та внутрішніх органів (Boiko et al., 2007; Marra et al., 2015; Nicolini et al., 2014).

На всіх етапах лікування адекватне дренування порожнини деструкції залишається одним із основних умов для одужання хворого або як етап передопераційної підготовки (Boiko et al., 2007; Safonov \& Shahov, 2015; Shoikhet et al., 2014). 3 точки зору фізіології системи дихання найбільш оптимальними методами дренування являються ендобронхіальні (бронхоскопічні) (Boiko et al., 2007; Cascone et al., 2020; Shoikhet et al., 2014). Перевагами ендобронхіальних методик лікування являються: малоінвазивність, збереження кашльового рефлексу, можливість проведення програмних санацій порожнини деструкції та дренуючих бронхів (Boiko et al., 2007; Cascone et al., 2020; Shoikhet et al., 2014; Unterman et al., 2017).

Одним із шляхів поліпшення результатів лікування хворих 3 хронічними абсцесами легень являється пошук нових способів лікування цього захворювання, зокрема за допомогою застосування різних лікарських комбінацій та корекції активності оксидантноантиоксидантної систем організму (Boiko et al., 2007; Boiko et al., 2015).

Частіше за все для динамічного контролю репаративних процесів у легеневій тканині використовуються променеві методи діагностики такі як рентгенографія та комп'ютерна томографія (КТ). На відміну від традиційних методів, ультразвукове дослідження (УЗД) необгрунтовано використовується досить рідко в торакальній хірургії та пульмонології. Хоча УЗД дозволяє отримувати таке саме двомірне зображення, як і КТ (Kotiv et al., 2009; Safonov \& Shahov, 2015).

Усі вище перелічені факти і послужили поштовхом для нашого дослідження.

Мета дослідження. Дослідити ефективність застосування ендобронхіальних методів у лікуванні хронічних абсцесів легень 3 використанням різних лікарських композицій.

\section{Методи:}

На базі відділення торако-абдомінальної хірургії ДУ "Інститут загальної та невідкладної хірургії ім. В. Т. Зайцева НАМН України" обстежено та проліковано 98 хворих з хронічними абсцесами легень. Усі хворі були розподілені на 2 групи. Першу групу (порівняння) склали 48 хворих, яким крім консервативного лікування, що включало протизапальну, антибактеріальну i дезінтоксикаційну терапію, здійснювалися традиційні підходи до ендобронхіальної санації вогнища гнійно-запального процесу. Другу групу (основну) склали 50 
хворих, яким виконували ендоскопічне дренування абсцесу за власною методикою під візуальним контролем 3 використанням рентгеноконтрастних катетерів 3 подальшою санацією порожнини деструкції. Хворим основної групи разом 3 протизапальними препаратами призначали ліпосомальний препарат “Ліпін”: системно (внутришньовенно у дозі 10 мг/кг ваги тіла) та місцево (інгаляційно, ендобронхіальні заливки та введення до порожнини деструкції у суміші з протизапальними препаратами).

Для оцінки ефективності лікування застосовували лабораторні та інструментальні методи дослідження. Серед лабораторних методів особливу увагу приділяли показникам ендогенної інтоксикації та перекисного окислення ліпідів (ПОЛ). Одними із найважливіших показників цих процесів $\epsilon$ рівень таких продуктів, як молекули середньої маси (МСМ), малоновий диальдегід (МДА), дієнові коньюгати (ДК), супероксиддисмутаза (СОД). Також вивчався показник лейкоцитарного індексу інтоксикації (ЛІІ). Порівняння проводили використовуючи критерій Стьюдента. 3 метою виявлення статистично достовірних даних у пацієнтів основної групи та групи порівняння ми використовували початкові (на момент госпіталізації) та проміжкові (на 10 добу лікування) значення вищевказаних параметрів. Інструментальний контроль ефективності лікування проводили за допомогою рентгенологічних методів дослідження (рентгенографія, комп'ютерна томографія) та ультразвукового дослідження (УЗД). Перевагу віддавали ультразвуковому дослідженню, як методу 3 найменшим шкідливим навантаженням на організм хворого. Ультразвуковими критеріями ефективності лікування вважали зменшення розмірів порожнини (позитивна ультразвукова динаміка) та появу ознак облітерації порожнини. Частота контрольних досліджень - 1 раз у три доби.

Ендобронхіальні лікувально-діагностичні методи виконували в умовах місцевої анестезії апаратом фірми Olympus BF TYPE 1T 180. Після проведення евакуації гнійного відокремлюємого та визначення дренуючого бронху нами, під рентгенологічним контролем, проводилась катетеризація устя дренуючого бронху або порожнини хронічного абсцесу поліхлорвініловим катетером.

\section{Результати:}

У процесі лікування хворих досліджуваних груп нами здійснювався динамічний контроль ефективності лікування.

При аналізі показників лабораторної ефективності комплексного лікування хворих на хронічні абсцеси легень із 
застосуванням запропонованої суміші протизапальних препаратів (гідрокортизону та гатіфлоксацину) та ліпосомального препарату “Ліпін” чітко відстежується суттєвий вплив запропонованої лікарської суміші на зниження рівня показників ендогенної інтоксикації та продуктів перекисного окислення ліпідів.

Так, у хворих основної групи відмічене достовірне зниження рівня МСМ $30.63 \pm 0.05$ до $0.32 \pm 0.01$ у.о., тоді як у хворих групи порівняння рівень МСМ знизився з $0.64 \pm 0.06$ до $0.56 \pm 0.04$ у.о., що у 1.75 рази більше $(\mathrm{p}<0.05)$. При порівнянні рівня показників ПОЛ - ДК та МДА видно, що рівень ДК у хворих основної групи знизився 3 $187.5 \pm 6.7$ до $114.3 \pm 5.2$ ммоль/л, що у 1.4 рази менше $(\mathrm{p}<0.05)$ ніж

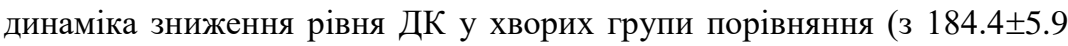
до 162.7 \pm 5.3 ммоль/л); рівень МДА знизився у хворих основної групи 3 $20.5 \pm 0.84$ до 9.78 \pm 0.25 ммоль/л, що у 1.6 рази менше $(\mathrm{p}<0.05)$ ніж

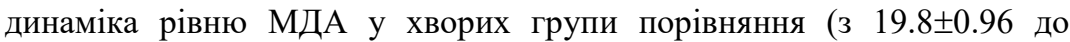
$15.2 \pm 0,85$ ммоль/л). При оцінюванні активності антиоксидантної системи було з'ясовано, що рівень СОД у хворих основної групи, під впливом запропонованого лікування, підвищився $3 \quad 17.6 \pm 3.4$ до $46.3 \pm 2.6$ од/г Нb, тоді як у хворих групи порівняння $317.7 \pm 3.2$ до $32.3 \pm 3.9$ од/г Нb, що у 1.4 рази менше $(\mathrm{p}<0.05)$. При порівнянні рівня ЛІІ, який обчислювался за формулою Кальф-Каліфа, у групах дослідження нами було з'ясовано, що у хворих основної групи на 10 добу лікування ЛІІ склав $1.49 \pm 0.62$, що у 3.7 рази менше $(\mathrm{p}<0.05)$ ніж на той же час у хворих групи порівняння (5.58土1.23).

Так як інструментальний контроль ефективності лікування проводили переважно за допомогою УЗД, нами були введені наступні ультразвукові (УЗ) критерії оцінки: 1) зменшення розмірів порожнини; 2) терміни очищення порожнини хронічного абсцесу; 3) ознаки часткової облітерації порожнини абсцесу - поява відкладень фібрину на стінках порожнини. Більша ефективність лікування відмічена у хворих основної групи, що проявилося в прискоренні очищення порожнини абсцесу $-7.85 \pm 0.34$ діб, що раніше на 2.3 доби $(\mathrm{p}<0.05)$ ніж у групі порівняння; прискоренні позитивної ультразвукової динаміки $8.9 \pm 0.59$ діб, що раніше на 2.9 доби $(\mathrm{p}<0.05)$ ніж у групі порівняння. Терміни часткової облітерації порожнини скоротилися в середньому на 3 доби: з 15.1 \pm 0.6 діб у хворих групи порівняння до $11.9 \pm 0.78$ діб у хворих основної групи. 


\section{Висновки:}

1. Отримані дані демонструють вірогідно більш високу ефективність запропонованого методу ендобронхіального лікування хворих на хронічні абсцеси легень, що включає комбінацію дренування та санації порожнини деструкції 3 протизапальною терапією та його перевагу перед стандартними схемами лікування, що супроводжувалося більш швидким статистично достовірним регресом патологічного процесу та суттєвим зниженням рівня ендогенної інтоксикацї.

2. Стандартні методи променевої діагностики при хронічних абсцесах легень необхідно більш широко доповнювати ультразвуковим дослідженням, особливо 3 метою динамічного спостереження під час лікувального процесу, що дозволяє значно знизити променеве навантаження на хворих.

\section{Conflicts of interests:}

The authors declare that there is no conflict of interests.

\section{Source of support:}

This research did not receive any outside funding or support.

\section{References}

Boiko, V. V., Florikyan, A. K., \& Avdosyev, Yu. V. (2007). Gnojnye zabolevanija legkih $i$ plevry [Purulent diseases of the lungs and pleura]. Prapor. [in Russian]

Boiko, V. V., Minukhin, D. V., \& Tarasenko, L. H. (2015). Zastosuvannia liposomalnykh likarskykh kompozytsii u likuvanni hniinodestruktyvnykh zakhvoriuvan lehen [The use of liposomal drug compositions in the treatment of purulent-destructive lung diseases]. Kharkivska khirurhichna shkola - Kharkiv Surgical School, 1(70), 55-58. [in Ukrainian]

Cascone, R., Sica, A., Sagnelli, C., Carlucci, A., Calogero, A., Santini, M., \& Fiorelli, A. (2020). Endoscopic treatment and pulmonary rehabilitation for management of lung abscess in elderly lymphoma patients. International Journal of Environmental Research and Public Health, 17(3), 997. https://doi.org/10.3390/ijerph17030997

Kotiv, B. N., Barinov, O. V., \& Saenko, O. Yu. (2009). Vozmozhnosti rentgenografii, UZI, KT dlja ocenki reparativnyh processov posle abscessov legkogo i jempiemy plevry [Possibilities of radiography, ultrasound, CT for assessing reparative processes after lung abscesses and pleural empyema]. Vestnik Rossijskoj voenno- 
medicinskoj akademii - Bulletin of the Russian Military Medical Academy, 4(28), 42-46. [in Russian]

Marra, A., Hillejan, L., \& Ukena, D. (2015). Behandlung von lungen abszess [Treatment of lung abscess]. Zentralblatt fur Chirurgie Central Sheet for Surgery, 140(suppl 1), 47-53. https://doi.org/10.1055/s-0035-1557883 [in German]

Nicolini, A., Cilloniz, C., Senarega, R., Ferraioli, G., \& Barlascini, C. (2014). Lung abscess due to Streptococcus pneumoniae: A case series and brief review of the literature. Advances in Respiratory Medicine, 82(3), 276-285. https://doi.org/10.5603/PiAP.2014.0033

Safonov, D. V., \& Shahov, B. E. (2015). Ultrazvukovaja diagnostika vospalitelnyh zabolevanij legkih [Ultrasound diagnostics of inflammatory lung diseases]. Mezhdunarodnyj zhurnal jeksperimentalnogo obrazovanija - International Journal of Experimental Education, 2(2), 195-196. [in Russian]

Shoikhet, Ya. N., Syzdykbaev, M. K., Kurtukov, V. A., \& Kapitulin, S. Yu. (2014). Selektivnaja transtrahealnaja kateterizacija bronhov v lechenii ostryh abscessov i gangren legkogo [Selective transtrakheal kateterization of bronchial tubes in treatment of sharp abscesses and gangrenes of a lung]. Sovremennye problemy nauki $i$ obrazovaniya - Modern Problems of Science and Education, 3, 472. [in Russian]

Unterman, A., $\quad$ Fruchter, O., $\quad$ Rosengarten, D., Izhakian, S., AbdelRahman, N., \& Kramer, M. R. (2017). Bronchoscopic drainage of lung abscesses using a pigtail catheter. Respiration, 93, 99-105. https://doi.org/10.1159/000453003

Wali, S. O. (2012). An update on the drainage of pyogenic lung abscesses. Annals of Thoracic Medicine, 7(1), 3-7. https://doi.org/10.4103/1817-1737.91552

\section{Information about the authors:}

Serenko Anton Andriiovych - https://orcid.org/0000-0002-6410-4509; Graduate Student, Department of Surgery of the Thoracic Cavity, State Institution "V. T. Zaitsev Institute of General and Urgent Surgery of the National Academy of Medical Sciences of Ukraine", Kharkiv, Ukraine.

Research interests: surgery, medical sciences.

Hroma Vasiliy Grigorovich - https://orcid.org/0000-0003-1886-3181; Doctor of Medical Sciences, MD, Professor, Professor of the Department of Surgery No. 1, Kharkiv National Medical University; Head of the Department of Operative Endoscopy, State Institution "V. T. Zaitsev 
Institute of General and Urgent Surgery of the National Academy of Medical Sciences of Ukraine", Kharkiv, Ukraine.

Research interests: surgery, education, medical sciences.

Minukhin Dmytro Valeriiovych - https://orcid.org/0000-0003-3371-1178;

Doctor of Philosophy in Medicine, Associate Professor, Associate Professor of the Department of Surgery No. 1, Kharkiv National Medical University, Research interests: surgery, education, medical sciences.

Yevtushenko Denys Oleksandrovych - https://orcid.org/0000-0003-19417183; Doctor of Medical Sciences, MD, Professor, Professor of the Department of Surgery No. 1, Kharkiv National Medical University, Research interests: surgery, education, medical sciences.

Cite this article as:

Serenko, A. A., Hroma, V. G., Minukhin, D. V., \& Yevtushenko, D. O. (2021). Suchasni endobronkhialni metody v likuvanni khronichnykh abstsesiv lehen [Modern endobronchial methods in the treatment of chronic lung abscesses]. In Yu. B. Melnyk, \& L. M. Georgieva (Eds.), Current Issues of Education and Science. 9th International Conference, CIES-2021, Riga, Latvia - Kharkiv, Ukraine, November 10-13, 2021, Conference proceedings (pp. 83-91).

$\mathrm{KRPOCH}$. https://doi.org/10.26697/9786177089147.2021.10 [in Ukrainian]

\section{Copyright information:}
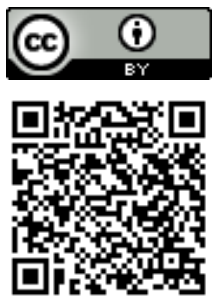

The published paper are licensed under a Creative Commons "Attribution" 4.0 Worldwide

The electronic version of this article is complete. Full or partial reproduction of article is allowed, citing to the source, author(s) and DOI. An electronic copy of the Conference proceedings in open access is available via the KRPOCH Publishing website https://publisher.culturehealth.org 